Bu makaleye atıfta bulunmak için/To cite this article

KALKAY, D. (2021). Enflasyon Hedeflemesi Stratejisi Uygulayan Ülkelerde Gerçekleşen Enflasyon Oranı ve Gelir

Dağılımı Arasındaki Illişki: Panel Veri Analizi. Atatürk Üniversitesi Sosyal Bilimler Enstitüsü Dergisi, 25 (3), 1200-1211.

\title{
Enflasyon Hedeflemesi Stratejisi Uygulayan Ülkelerde Gerçekleşen Enflasyon Oranı ve Gelir Dağılımı Arasındaki İlişki: Panel Veri Analizi
}

\author{
Duygu KALKAY ${ }^{(*)}$
}

\begin{abstract}
Öz: Toplumların ekonomik ve sosyal refahı için fiyat istikrarının sağlanması oldukça önemlidir. Bu nedenle, gelişmiş veya gelişmekte olan ülkelerde fiyat istikrarını sağlamaya yönelik birçok strateji uygulanmıştır. Enflasyon hedeflemesi stratejisi de bunlardan biridir. Enflasyon hedeflemesinin temel amacı fiyat istikrarı sağlamak ve devam ettirmektir. Fiyat istikrarl, ülke ekonomilerinin düzgün işleyebilmesi için birincil koşuldur. Bir ekonominin sağllkl işlediğinin göstergelerinden biri de adil gelir dağılımıdır. Gelir dă̆glımındaki eşitsizlik, gelişmiş ülkelerde bile önemli bir sorun olmaya devam etmektedir. Literatürde, enflasyon orant, ekonomik büyüme ve işsizlik oranı ile gelir dă̆glımı arasındaki ilişki birçok defa analiz edilmesine rağmen, bu ilişkiyi enflasyon hedeflemesi kapsamında inceleyen çalışma bulunmamaktadır. Bu çalışmada, enflasyon hedeflemesi stratejisi uygulayan 8 gelişmiş ve Türkiye'nin de dahil edildiği 8 gelişmekte olan toplamda 16 ülkenin 2002-2016 yilları arasinda gerçekleşen enflasyon oranı ve gelir dă̆ılımı arasındaki ilişski panel veri analizi ile sınanmıştır. Modelin anlamlı ve bir bütün olarak yorumlanabilmesi için büyüme ve işsizlik oranları da modele dahil edilmiştir. Birim etkili sabit etkiler modeli için gerekli varsayım testleri sınanmış olup, Driscoll-Kraay Standart Hatalar Tahmincisi ile varsayımdan sapmalar düzeltilerek nihai yorumlanacak ekonometrik model elde edilmiştir. Buna göre enflasyon ve işsizlik oranları yükseldikçe gelir dağılımının bozulduğu sonucuna varllmıştır.
\end{abstract}

Anahtar Kelimeler: Gelir dağılımı, enflasyon hedeflemesi, panel veri analizi

\section{The Relationship Between Inflation Rate and Income Distribution in Countries Implementing Inflation Targeting Strategy: Panel Data Analysis}

\begin{abstract}
Ensuring price stability is very important for the economic and social welfare of societies. Therefore, many strategies have been implemented in developed or developing countries to ensure price stability. Inflation targeting strategy is one of them. The main objective of inflation targeting is to obtain and maintain price stability. Price stability is the primary condition for the smooth functioning of country's economies. One of the indicators of the proper functioning of an economy is fair income distribution. The inequality of income distribution continues to be an important problem even in developed countries. Although the relationship between inflation rate, economic growth and unemployment rate has been analyzed many times in the literature, there is
\end{abstract}

\footnotetext{
*)Öğretim Görevlisi, Bandırma Onyedi Eylül Üniversitesi Sağlık Hizmetleri MYO (e-posta: dkalkay@bandirma.edu.tr) (D) ORCID ID. https://orcid.org/0000-0002-8729-9177

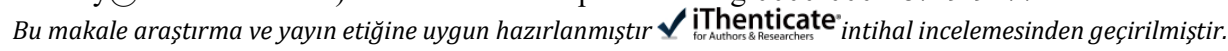


no study on this relationship with inflation targetingin this study, the relationship between income distribution and inflation rate being from 2002 to 2016 of 16 countries which are 8 developing countries included turkey and 8 developed countries implementing an inflation targeting strategy was tested with panel data analysisGrowth and unemployment rates are also included in the model so that the model can be interpreted meaningfully and as a whole. Tests of conjecture which is necessary for the unit influential fixed effects model have been analyzed. Also The econometric model to be interpreted in the final has been created by rectifying deviations from the DriscollKraay which is the estimator of the standard errors and from the assumptionAccordingly, it was concluded that income distribution were deteriorated as inflation and unemployment rate increased.

Keywords: Income distribution, inflation targeting, panel data analysis

Makale Geliş Tarihi: 29.06.2021

Makale Kabul Tarihi: 19.09.2021

DOI: 10.53487/ataunisosbil.95970

\section{Giriș}

Ülke ekonomileri için olmazsa olmazlar vardır. Bunların en başında fiyat istikrarını sağlamak ve bunun getirisi olarak da kişi başına düşen gelirin artmasını sağlamaktır. Ülkeler statülerine göre kategorilere ayrılırken, genellikle belirleyicilerin başında enflasyon ve kişi başına düşen gelir yer almaktadır. Bu nedenle fiyat istikrarı ülke ekonomileri için oldukça önemlidir. Enflasyon hedeflemesi stratejisinin asıl amacı fiyat istikrarını sağlamak ve devam ettirmektir. Fiyat istikrarı; ülke ekonomilerinin düzgün işleyebilmesi, yani makroekonomik göstergelerde istikrarın sağlanabilmesi açısından oldukça önemlidir. Ekonomiler için elde edilen gelir veya refah düzeyinin artırılması kadar önemli olan bir başka nokta ise, elde edilen bu gelir veya refahın nasıl bölüşüldüğüdür. Çünkü gelir dağılımı adaletsizliği sadece ekonomik sorunlara yol açmaz, bununla birlikte birçok toplumsal problemi de beraberinde getirir. Enflasyon ve gelir dağılımı birbirileri ile doğrudan bağlantılı olmasa bile diğer bir ifade ile ekonomiler için farklı uçlarda olsa da önem dereceleri birbirileriyle kıyaslanabilir seviyededir. Yapılan çalışmalarda yüksek enflasyon oranlarının gelir dağıılımı adaletini direkt olarak negatif etkiler sonucu çıkmasa da yüksek enflasyon oranlarının sebep olduğu olayların sonucunda gelir dağılımı adaletinin bozulduğu sonucuna ulaşılmaktadır.

Ülke ekonomilerinin geleceğe dair daha uygulanabilir kararlar almalarını sağlamak, düşük ve sürdürülebilir bir enflasyon düzeyi tutturabilmek amacıyla, enflasyon hedeflemesi stratejisi 1989 yılında Yeni Zelanda tarafindan ilk defa uygulanmaya başlanmıştır. Enflasyon hedeflemesi stratejisinin Yeni Zelanda'da başarılı sonuçlar vermesiyle birlikte $2000^{\prime} l i$ yılları takiben öncelikle gelişmiş ülkeler ve daha sonrasında ise gelişmekte olan ülkeler tarafindan enflasyon hedeflemesi (inflation targeting) stratejisi benimsenmeye başlanmıştır. Enflasyon hedeflemesi uygulaması; merkez bankasının temel hedefi olan fiyat istikrarının elde edilmesi ve devamına yönelik para politikasının makul bir dönem için belirlenen sayısal bir enflasyon hedefi veya hedef aralığına dayandırılması ve bunun kamuoyuna ilan edilmesi olarak ifade edilen para politikası uygulamasıdır. Enflasyon hedeflemesi rejiminde merkez bankaları ile hükümetler arasında anlaşmalar yapılmaktadır. Gelişmiş bir ülke ile gelişmekte olan bir 
Enflasyon Hedeflemesi Stratejisi Uygulayan Ülkelerde Gerçekleșen Enflasyon Oranı ve Gelir Dağılımı Arasındaki İlișki: Panel Veri Analizi

ülkenin piyasa şartları aynı olmadığı için, ülke şartlarına göre bu uygulamada farklılıklar olmaktadır.

Enflasyon hedeflemesi stratejisinin istenilen başarıyı elde edebilmesi için üç ön koşula sahip olması gerekir. Bunları; para politikasının fiyat istikrarı amacına odaklanması, merkez bankasının bağımsız olması ve gelişmiş mali piyasaların varlığı olarak sayabiliriz. Enflasyon hedeflemesi, bağımsız merkez bankaları tarafından yürütülen, ara hedef yerine enflasyon tahminlerinin kullanıldığı, stratejinin uygulama aşamasında şeffaflık, hesap verebilirlik ve güvenirlilik esaslarının olduğu bir para politikası uygulamasıdır. Ülke ekonomileri makroekonomik göstergelerin başında yer alan büyüme, işsizlik ve enflasyon oranlarını yakından takip eder. Kısa dönemde enflasyon ve işsizlik gibi ekonomik problemler ile daha çok uzun vadede gelir dağılımı ile bağlantılı olan büyüme oranları ciddi sorunlara sebep olabilmektedir. Bir ülkede ekonomik büyüme yaşanırken bunun yanında işsizlik ve enflasyon oranının düşmesi, bu ülkede bireylerin alım güçlerinin artış eğiliminde olduğu şeklinde yorumlanır. Ancak ekonomik büyüme oranında meydana gelen artışa oranla enflasyon ve işsizlik oranında önemli bir düşüş olmaması, ekonomik büyüme sayesinde artan milli gelirin ülke vatandaşları arasında eşit dağılmadığını gösterir. Yani milli gelirin daha çok belirli bir kesime giderek bu kitlenin gelirinin artığı, yani ülke içinde gelir dağılımı adaletsizliğinin yaşandığını gösterir (Şentürk ve Akbaş, 2014: 5821).

Yüksek ve sürekli hale gelen enflasyon, ülke ekonomilerini birçok yönden olumsuz etkilemiştir. Özellikle Türkiye'nin de içinde bulunduğu gelişmekte olan ülkelerde hem siyasi hem toplumsal sebeplerden dolayı enflasyonla mücadele için daha çok kısa vadeli politikalar uygulanmaktadır. Bunun sonucu olarak da ekonomi ve toplum birçok yönden olumsuz etkilenmektedir. Bu etkilerin gelir dağılımına yansıması her ne kadar ekonomik olsa da gelir dağılımının sonuçları ekonomik olduğu kadar toplumsaldır. Çünkü gelir dağılımı adaletsizliği artması sonucunda toplumlarda birçok sorun baş göstermektedir. Gelir dağılımı gelişmiş veya gelişmekte olan ülkeler için en önemli tartışma konularından biridir. Özellikle son dönemlerde, ülke ekonomilerinde gelirin artmasına rağmen gelir dağılımı eşitsizliğinin giderek artması konunun önemini daha da arttırmaktadır. Yani ülke ekonomilerinde büyüme ve toplam gelir artarken bu artışın çoğunlukla belirli bir kesime gitmesi ve sonuçta zengin fakir arasındaki uçurumun artması ekonomik sorunlar yanında siyasi ve toplumsal sorunları da beraberinde getirmektedir.

Enflasyon genel olarak fiyatlar genel seviyesindeki sürekli artışlar olarak tanımlanır. $\mathrm{Bu}$ sebeple gelirlerini fiyat artışları karşısında koruyamayanlar enflasyon sebebiyle bir gelir kaybı yaşarlar. Genelde sabit ve düşük gelir grubundakilerin gelirleri enflasyona karşı direnemez. Aslında yapılan çalışmalar ve gözlemler ortaya koyuyor ki gelir dağılımı yüksek enflasyonla birlikte bozulmaktadır. Yani aralarında negatif bir ilişki konusudur. Ancak her ne kadar genel sonuç böyle olsa da aralarında herhangi bir etkileşim olmadığını ortaya koyan çalışmalarda mevuttur (Ataman Erdönmez ve Alparslan, 2000: 39).

İktisadın kurucularından Adam Smith ve David Ricardo'dan itibaren, üretimden elde edilen gelirin adaletli bir şekilde kişiler arasında nasıl paylaşılacağı üzerinde çok sayıda tartışma olmuştur. Yani gelir dağılımı adaletsizliği konusu geçmişten günümüze dünya 
ekonomilerinin, özellikle de Türkiye gibi gelişmekte olan ülkelerin en önemli ekonomik problemleri arasındadır. Gelir dağılımı adaletsizliği toplumsal birçok problemin çıkış noktası olması sebebiyle, yaşanan siyasi istikrarsızlıkların ekonomiye yansımasının genel sonucu olarak görülmektedir. Toplumsal bakımdan oldukça önemli, ekonomik ve sosyal maliyeti olan böylesine derin ve büyük bir problemin giderilmesi için ülkeler tarafından birçok iktisadi politika izlenmiştir (Eroğlu, Altaş, Ün ve Ulu, 2017: 366).

Çalışmada, ekonomik büyüme, enflasyon ve işsizliğin birbiriyle olan ilişkilerine değinilerek, gelir dağılımına adaleti üzerindeki yansımalarına yer verilmiştir. Çalışmada öncelikle ülkelerin neden enflasyon hedeflemesi stratejisi uyguladığına değinilmiş̧ir. Daha sonra fiyat istikranın; büyüme, enflasyon, işsizlik ve gelir dağılımı ile arasındaki ilişki incelenmiştir. Ayrıca enflasyon ve gelir dağılımı arasındaki ilişkinin araştırıldığı literatürdeki çalışmalara yer verilmiştir. Sonraki bölümde ise, gelişmiş ve Türkiye'nin de dahil edildiği gelişmekte olan toplamda 16 ülkenin 2002-2016 yılları arasında gerçekleşen enflasyon, büyüme ve işsizlik oranlarının gelir dağılımı üzerinde etkisi, panel veri analizi ile test edilmiştir. Son olarak da elde edilen ekonometrik sonuçlar yorumlanarak politika önerileri sunulmuştur.

\section{Literatür Taraması}

Literatür incelendiğinde gelir dağılımı konusunda birçok çalışmaya rastlanmaktadır. Başta enflasyon, büyüme, kamu gelirleri, vergiler ve teknolojik değişme gibi ekonomik göstergeler ile gelir dağılımı arasındaki ilişki birçok defa incelenmiştir. Gelir dağı̆lımı ile ilgili gelişmiş veya gelişmekte olan ülkelerde birçok çalışma mevcuttur. Yapılan çalışmaların çoğunda gelir eşitsizliği ve büyüme arasındaki karşlıklı ilişki incelenmiştir. Ancak gelir dağılımı hakkında yapılan çalışmalarda ekonometrik analizlerde kullanılacak olan verilere ulaşabilme güçlügü büyük sıkıntı yaratmaktadır. Bu kapsamda aynı veriler üzerinde yapılan kısıtlı çalışmalarda da gelir eşitsizliği ile büyüme oranları arasında farklı sonuçlara ulaşılmaktadır. Bu durumda aynı verilerle birbiri ile tutarsız sonuçlara ulaşılabilmektedir. Gelir dağılımı ile ilgili yapılan çalışmalarda farklı farklı sonuçlara ulaşılmasının altında veri problemi yatmaktadır. Gelir dağılımını adaletini gösteren veriler tek tip olarak yayımlanmadığı için, bazı çalışmalarda pozitif iliş̧ki çıkarken bazı çalışmalarda negatif veya ilişkisiz çıkabilmektedir.

Gelir dağılımı ve büyüme arasındaki ilişki karşılıklı olarak da birçok defa sınanmıştır. Yani kimi çalışmalarda gelir dağılımının büyüme üzerindeki etkisi incelenirken, kimi çalışmalarda ise gelir dağllımın büyüme üzerinde etkisi ortaya konmuştur. Branco ve Williams (1988) yaptıkları çalı̧̧a, büyümenin gelir dağılımı üzerindeki etkisini inceleyen önemli araştırmalardandır. Çalışmada asıl amaç iktisadi olarak elde edilen büyümenin nüfusun en düşük gelirli olan $\% 40$ 'da meydana getirdiği değişmeyi ortaya koymaktır. Gelişmekte olan ülkelerden 54 'ü ile gelişmiş ülkelerden 14'ü üzerinde yapılan çalışmada, başlangıçta büyümenin nüfusun en yoksul \%40'inın gelirinin azalttı̆̆ 1 görülmüştür. Başka bir ifadeyle gelir dağılımı ve büyümenin arasında negatif ilişki olduğu sonucuna varılmıştır.

Gelir dağglımı ile büyüme arasındaki ilişkiyi inceleyen diğer bir çalışmada Persson ve Tabellini (1994), gelir dağılımı eşitsizliğinin büyüme üzerindeki etkisini genel denge modeli ile ele almışlardır. Gelişmiş ve gelişmekte olan ülkeler için ayrı ayrı analiz 
Enflasyon Hedeflemesi Stratejisi Uygulayan Ülkelerde Gerçekleşen Enflasyon Oranı ve Gelir Dağılımı Arasındaki İlișki: Panel Veri Analizi

yapılarak, gelir dağılımı ile büyüme arasında negatif bir ilişki olduğu sonucuna varmışlardır.

Doğan ve Akbakay (2016), enflasyon hedeflemesi ile ilgili yaptıkları çalışmada, fiyat istikrarının ülke ekonomilerine yaptığı katkı ülkeler çapında değerlendirilmiştir. Dişbudak ve Süslü (2008), Türkiye'de bireysel gelir dağılımını etkileyen makroekonomik unsurlarla, enflasyon oranlarının gelir dağılımı üzerindeki negatif etkisini ele almışlardır.

Panizza (2002), ABD eyaletlerinde 1940-1080 yılları arasında gelir dağılımı ile büyüme arasındaki ilişkiyi panel veri yöntemiyle analiz etmiş olup, çalışmada büyüme ve gelir dağılımı eşitsizliği arasında negatif ilişki çıkmasına rağmen, bu ilişkinin zayıf bir ilişki olduğu sonucuna varmıştır.

Güder ve Kurt (2018), makroekonomik değişkenlerin gelir adaletsizliği üzerine etkilerini BRIC-T ülkeleri için panel veri analizi ile sınayan çalışmalarında; kamu gelirleri, ekonomik küreselleşme endeksi ve enflasyonun gelir dağılımını olumsuz yönde etkilediği sonucuna ulaşmışlardır. Çalışmanın özelinde enflasyonnun gelir dağılımı üzerindeki etkisi, literatürdeki çoğu çalışma da olduğu gibi enflasyonun reel ücretleri düşürmesi nedeniyle özellikle düşük gelirliler açısından gelir dağılımını bozduğu sonucuna varılmıștır.

Şentürk ve Akbaş (2014), 1963-1998 yılları arasında Türkiye'de Bütçe Dengesi, Kişi Başına Gelir, Dışa Açıklık ve Enflasyon gibi kişisel gelir dağılımını etkileyen değişkenlerin etkisi zaman serisi analizi ile test edilmiştir. Regresyon sonucuna göre, Büyüme başta gelir dağılımı üzerinde negatif etki yaratırken, uzun dönemde olumlu etki yaratmaktadır. Ayrıca enflasyon oranlarında yaşanan artışların, az da olsa gelir dağılımı adaletini bozduğu görülmüştür.

Bulir (2001) gelir dağılımı ve enflasyon arasındaki ilişkiyi 22 yıl için 75 ülke verilerini kullanarak panel veri analiz yöntemiyle test etmiştir. Yüksek enflasyon oranlarının gelir dağılımını negatif yönde etkilediğini, düşük enflasyon oranlarının gelir dağılımını olumlu yönde etkilediğini sonucunu ortaya koymuştur. Farklı bir çalışma olarak, Pierre Monnin (2014), 1971-2010 yılları arasında seçilmiş 10 OECD ülkesi için zaman serisi yöntemiyle gelir eşitsizliği ile enflasyon arasındaki ilişkiyi test etmiştir. Sonuç olarak düşük enflasyon seviyelerinde gelir eşitsizliğinin yüksek olduğu ve enflasyonun artmasıyla bu eşitsizliğin azaldığı görüşmüştür. Ancak bu eşitsizlik, enflasyonun \%13 düzeylerinde minimuma ulaştıktan sonra tekrar yükseldiği sonucuna varılmıştır.

Akyazı ve Ekinci (2008), Enflasyon hedeflemesi stratejisini uygulayan ve Türkiye'nin de içinde yer aldığ 1 toplamda 13 gelişmekte olan ülke verileri analiz edilmiştir. Bu seçili ülkeler ile Türkiye'nin enflasyon oranı ve yansımaları olarak üretim performansları kıyaslanmıştır. Çalışma sonucunda enflasyon hedeflemesi ile birlikte Türkiye de kısmen de olsa enflasyon bakımından daha istikrarlı olduğu ve diğer ülkelere kıyasla daha başarılı olduğu sonucuna varılmıştır.

Öztürk (2009), gelişmiş ve gelişmekte olan ülkelerde enflasyon hedeflemesi stratejisinin başarısını ele almış ve sonuç olarak uygulanan bütün ülkelerde genel olarak enflasyonu önemli düzeyde olumlu yönde etkilediği sonucuna ulaşılmıştır. Ayrıca enflasyon hedeflemesi uygulama sürecinde gelişmekte olan ülkelerin büyüme 
oranlarının, gelişmiş ülkelere göre daha yüksek oranlarda olmasını sağladığı da ayrıca belirtilmiştir. Büyüme oranları olarak gelişmekte olan ülkeler, gelişmiş ülkeler düzeyini yakalayamasalar da, uygulanan strateji sayesinde enflasyon oranlarını düşürmeyi başardıkları için, ekonomik istikrarın oluşumuna ciddi etki yaptığı ayrıca belirtilmiştir.

\section{Ekonomik Analiz: Veri Seti ve Yöntem}

A. Veri seti

Çalışmada veri seti, enflasyon hedeflemesi stratejisi uygulayan 8 gelişmiş ülke ve 8 gelişmekte olan toplam 16 ülkenin 2002-2016 yılları arasındaki Gini katsayıları bağımlı değişken, gerçekleşen enflasyon oranları, büyüme oranları ve işsizlik oranları da bağımsız değişken olarak belirlenmiştir. Enflasyon hedeflemesi stratejisi uygulayan ülkelerden özellikle verilerine ulaşılabilen Yeni Zellanda, Kanada, İngiltere, İsveç, Avustralya, İsrail, Çek Cumhuriyeti ve Norveç gelişmiş ülke olarak ele alınmış olup, Türkiye, Brezilya, Şili, Polonya, Colombiya Güney Afrika, Meksika ve Peru da gelişmekte olan ülkeler olarak analize dahil edilmiştir.

Çalışmada, veri setinin sınırlı tutulmasının en önemli sebebi, özellikle gelişmekte olan ülkelerin gelir dağılımı eşitsizliğini gösteren Gini katsayısına ulaşılamamasıdır Türkiye'nin 2002 y1lı itibariyle enflasyon hedeflemesi stratejisi benimsemesi sebebi ile veri setinin dönem aralığ $2002-2016$ olarak belirlenmiştir. Literatür taraması neticesinde, bağımlı değişken olarak gelir dağılımının belirlendiği çoğu çalışmada gelir dağılımını temsilen Gini katsayı oranları kullanılmıştır. Gini kat sayısı sıfır ile bir arasında değerler almakta olup, bire yaklaştıkça ülkede gelir dağılımının bozulduğu, sıfıra yaklaştıkça da gelir dağılımının düzeldiğini göstermektedir. Sonuç olarak, enflasyon hedeflemesi stratejisi uygulayan ülkelerde özelikle gerçekleşen enflasyon oranının gelir dağılımı üzerindeki etkisi orta konmaya çalışılacaktır. Enflasyon oranın yanında büyüme ve işsizlik oranları da bağımsız değişken olarak modele dahil edilmiş olup, gelir dağılımı üzerinde etkileri ortaya konmaya çalışılmış olup oluşturulan model aşağıdadır.

$\operatorname{LGini}_{i t}=\alpha+\beta_{1} E n f_{i t}+\beta_{2} \operatorname{gdp}_{i t}+\beta_{3}$ emple $_{i t}+\varepsilon_{i t}$

$i$ : Ülkeleri

\section{$t: Z a m a n$}

\section{L: Ait Olduğu Değişsenin Logaritması}

Tablo 1: Veriler

\begin{tabular}{llc}
\hline Değişken & Bilgi & Kaynak \\
\hline Gini Katsayısı & Standartlaştırılmış Dünya & SWIID \\
(Bağımlı Değişken) & Gelir Eşitsizliği & \\
& Veritabanının (SWIID) & IMF \\
Enflasyon Oranı (Bağımsız Değişken) & Uluslararası Para Fonu & IMF \\
Büyüme Oranı (Bağımsız Değişken) & Uluslararası Para Fonu & IMF \\
İşsizlik Oranı (Bağımız Değişken) & Uluslararası Para Fonu & \\
\hline
\end{tabular}


Enflasyon Hedeflemesi Stratejisi Uygulayan Ülkelerde Gerçekleșen Enflasyon Oranı ve Gelir Dağılımı Arasındaki İlișki: Panel Veri Analizi

\section{B. Yöntem}

Panel veri; ülkeler, bireyler, firmalar gibi birimler için yapılan yatay kesit gözlemlerin, belirli bir dönem için bir araya getirilmesi ve değişkenler arasındaki iktisadi ilişkilerin tahmin edilmesi olarak tanımı yapılmaktadır. Zaman ve yatay kesit verilerini yapısı itibariyle birlikte kullanabilmeyi sağlayan panel veri analizi, farklı verilerle daha yüksek serbestlik derecesi ile tahminler yapma firsatı sunmaktadır. Panel veri modelleri parametrelerin birim ve/veya zamana göre değer almasına göre sınıflandırılır.

- Sabit ve eğim parametrelerinin zaman ve birimlere göre sabit olduğu klasik model,

- Eğim katsayısının sabit, sabit katsayının birimlere veya zamana göre değiştiği model tek yönlü (birim etkili veya zaman etkili) modeller,

- Birim ve zamana göre değiştiği model ise iki yönlü panel veri modeli şeklinde tanımlanmaktadır (Tatoğlu, 2018).

Tanımlama hatasını test etmek için geliştirilen Hausman spesifikasyon testi farklı alanlarda da uygulanmaktadır. Bu alanlardan biri, panel veri modellerinde hangi tahmincinin seçilmesi gerektiği aşamasında kullanılmaktadır. Sabit ve Tesadüfü model seçimi yapılırken, birim(zaman) etkilerle bağımsız değişkenler arasında korelesyon var ise sabit etkiler modeli, yok ise tesadüfü etkiler modeli geçerlidir. Sabit etkiler modeli için grup içi tahmincisinin tesadüfi etkiler modeli için ise en küçük kareler tahmincisine karşı test edilmesini sağlayan Hausman testinin temel hipotezi ("bağımsız değişkenler ile birim etki arasında korelasyon vardır") reddedildiği takdirde tesadüfi etkiler tahmincisinin sapmalı olduğu, sabit etkiler tahmincisinin ise tutarlı olduğudur. (Tatoğlu, 2018: 184-185)

IV. Tahmin sonuçları

Çalışmada Enflasyon Hedeflemesi Stratejisi uygulayan ülke verileri Stata.14 paket program kullanılarak panel regresyon analizi yapılmıştır. Yapılan analizde öncelikle modelde birim etki olup olmadığ 1 test edilmiştir. Modelde birim ve/veya zaman etkinin olup olmadığı sınamak için yapılan F (sabit Etkiler Modeli), LM (Tesadüfü Etkiler Modeli) ve LR (Tesadüfü Etkiler Modeli) en çok olabilirlik testleri ile yapılmıştır. Üç testin sonucuna göre de modelde birim etkinin olduğu görülmüş olup, modelin tek yönlü birim etkili panel veri modeli olduğu sonucuna varılmıştır.

Tablo 2: Tahmin Sonuçları

\begin{tabular}{|c|c|c|c|c|c|c|}
\hline \multirow[t]{2}{*}{ Gini } & \multicolumn{2}{|c|}{$\begin{array}{l}\text { Tesadüfi Etkiler Modeli LR } \\
\text { Testi) }\end{array}$} & \multicolumn{4}{|c|}{ 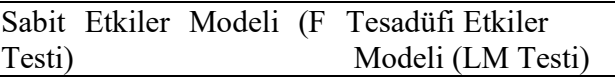 } \\
\hline & Katsayı & $\mathbf{P}>|\mathbf{t}|$ & Katsayı & $\mathbf{P}>|\mathbf{t}|$ & Katsayı & $\mathbf{P}>|\mathbf{t}|$ \\
\hline Iflation & .0022571 & 0.312 & .0017996 & 0.021 & .0018728 & 0.017 \\
\hline GDP & .002673 & 0.221 & .0024291 & 0.001 & 0024682 & 0.001 \\
\hline Emple & .008437 & 0.001 & .0073334 & 0.000 & .007514 & 0.000 \\
\hline Sabit & 3.520364 & 0.000 & 3.532266 & 0.000 & 3.530327 & 0.000 \\
\hline$R^{2}$ & & & \multicolumn{2}{|c|}{0.4105} & \multicolumn{2}{|c|}{0.3792} \\
\hline $\mathrm{F}$ & \multicolumn{2}{|c|}{$\begin{array}{l}212.42 \\
r>F=0.000\end{array}$} & \multicolumn{2}{|c|}{$\begin{array}{c}25,07 \\
\operatorname{Pr}>\mathrm{F}=0.000\end{array}$} & \multicolumn{2}{|c|}{$\begin{array}{c}77.46 \\
\operatorname{Pr}>F=0.000\end{array}$} \\
\hline
\end{tabular}


İkinci olarak birim etkinin olduğu sabit etkiler ve tesadüfi etkiler modellerinden hangisinin daha uygun olduğuna karar vermek için Hausman testi uygulanmıştır. Çalışmada kullanılan model için Hausman testinin temel hipotezi reddedilmiş ve alternatif hipotezde belirtildiği gibi modelin sabit etkiler modeli olduğu sonucuna ulaşılmıştır (Bkz.Tablo 3).

Ho: Tesadüfi etkiler modeli geçerlidir.

$\mathbf{H}_{1}$ : Sabit etkiler modeli geçerlidir.

Tablo 3: Hausman Testi Sonucu

\begin{tabular}{|c|c|}
\hline $\begin{array}{c}\text { Hausman test } \\
H_{o}: E\left(X_{i t}, \mu_{i} \neq 0\right)\end{array}$ & 9.23 \\
\hline
\end{tabular}

Üçüncü olarak belirlenen sabit etkiler modeli üzerinde temel varsayım testleri yapılarak (heteroskedasite, otokorelasyon ve birimler arası korelasyon) varsayımlardan sapmaları sınanmıştır (Bkz. Tablo 4).

Tablo 4: Sabit Etkiler Modeli

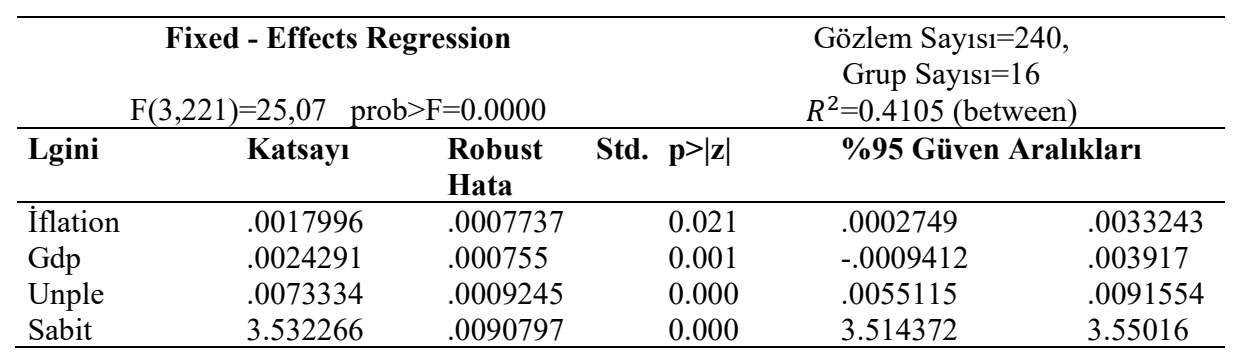

Tablo 5: Temel Varsayım Testleri

\begin{tabular}{|l|l|c|}
\hline Heteroskedasite & $\begin{array}{l}\text { Wald Test } \\
\left(H_{o}: \sigma_{i^{2}}=\sigma^{2}\right)\end{array}$ & $\begin{array}{c}\text { chi2(16) }=2731.82 \\
\text { Prob }>\text { chi2 }=0.0000\end{array}$ \\
\hline \multirow{5}{*}{ Otokorelasyon } & $\begin{array}{l}\text { Bhargava, Franzini ve } \\
\text { Narendranatha'ın } \\
\text { Durbin Watson Testi }\end{array}$ & 0.29408669 \\
\cline { 2 - 3 } & Baltagi-Wu LBI & 0.54154677 \\
\hline \multirow{5}{*}{ Birimler Aras1 Korelasyon } & Pesaran'1n Testi & $\begin{array}{c}1.687 \\
\operatorname{Pr}=0.0917\end{array}$ \\
\cline { 2 - 3 } & Friedman'in Testi & $\begin{array}{c}26.825 \\
\operatorname{Pr}=0.0302\end{array}$ \\
\cline { 2 - 3 } & Frees'in Testi & $\begin{array}{c}3.156 \\
\text { alpha }=0.10: 0.1719 \\
\text { alpha }=0.05: 0.2262 \\
\text { alpha }=0.01: 0.3351\end{array}$ \\
\hline
\end{tabular}

Temel varsayım test sonuçlarına göre otokorelasyon, heteroskedasite ve birimler arası korelasyonun varlığ 1 tespit edilmiştir. Tespit edilen varsayımdan sapmalar karşısında Driscoll-Kraay Dirençli Standart Hatalar Tahmincisi kullanılarak dirençli 
Enflasyon Hedeflemesi Stratejisi Uygulayan Ülkelerde Gerçekleșen Enflasyon Oranı ve Gelir Dağılımı Arasındaki İlișki: Panel Veri Analizi

tahminciler hesaplanmış ve iktisadi olarak yorumlanacak nihai model elde edilmiştir. Sabit etkiler modelinde tabloda verilen Wald test istatistiği ile H_o: $\sigma_{-}\left(\mathrm{i}^{\wedge} 2\right)=\sigma^{\wedge} 2$ hipotezi 16 serbestlik dereceli $\chi^{\wedge} 2$ değeri ve olasılık değerine göre reddedilmekte varyansın birimlere göre değiştiği ve heteroskedasitenin varlığı anlaşılmaktadır.

Otokorelasyon sınaması için ise tabloda belirtilen test istatistiklerinin (DW, LBI) kritik değer 2' den küçük olması, $H_{0}: \rho=0$ temel hipotezinin reddedildiğini sabit etkiler modelinde birinci mertebeden otokorelasyon olduğunu göstermektedir. Tablo 3 'te birimler arası korelasyonsuzluğu test eden testlerden Friedman ve Fress testlerine göre yatay kesit birimlerin kalıntılarına ait korelasyon matrisinin birim matris olduğu hipotezi reddedilmiş ve birimler arası korelasyon olduğu sonucuna ulaşılmıştır. Modelde varsayımdan sapmaları Driscoll-Kraay Standart Hatalar Tahmincisi ile düzeltilerek nihai model elde edilmiştir (Bkz. Tablo 6-7)

Tablo 6: Driscoll-Kraay Standart Hatalar Tahmincisi Sonuçları

\begin{tabular}{|c|c|c|c|c|c|}
\hline \multicolumn{3}{|c|}{ Fixed - Effects Regre } & \multicolumn{3}{|c|}{$\begin{array}{l}\text { Gözlem Say1s1 }=240, \\
\text { Grup Say1s1 }=16 \\
R^{2}=0.2539 \text { (within) } \\
R^{2}=00.4105 \text { (between) }\end{array}$} \\
\hline Lgini & & $\begin{array}{ll}\text { Robust } \\
\text { Hata }\end{array}$ & $\mathbf{p}>|\mathbf{z}|$ & \%95 Güv & Iarı \\
\hline Iflation & .0017996 & .00065 & 0.015 & .0004055 & .0031938 \\
\hline Gdp & .0024291 & 0015755 & 0.145 & -.0009499 & .0058081 \\
\hline Unple & .0073334 & .0011055 & 0.000 & .0049625 & .0097044 \\
\hline Sabit & 3.532266 & .0131698 & 0.000 & 3.50402 & 3.560513 \\
\hline
\end{tabular}

Tablo 7: Driscoll-Kraay Standart Hatalar Tahmincisi Sonuçları (Nihai Model)

\begin{tabular}{|c|c|c|c|c|c|}
\hline \multicolumn{3}{|c|}{\begin{tabular}{|l} 
Fixed - Effects Regression \\
$\mathrm{F}(3,14)=61.29$ prob $>\mathrm{F}=0.0000$
\end{tabular}} & \multicolumn{3}{|c|}{$\begin{array}{l}\text { Gözlem Sayısı=240, Grup Sayısı=16 } \\
R^{2}=0.2539 \text { (within) } \\
R^{2}=00.4105 \text { between) }\end{array}$} \\
\hline Lgini & Katsayı & Robust Std. Hata & $\mathbf{p}>|\mathbf{z}|$ & $\% 95$ Gü & alıkları \\
\hline Iflation & .0018931 & .0007262 & 0.021 & .0003355 & .0034506 \\
\hline Unple & 0070885 & .0011937 & 0.000 & .0045282 & .0096488 \\
\hline Sabit & 3.541742 & .0104964 & 0.000 & 3.51923 & 3.564255 \\
\hline
\end{tabular}

Tablo 6'da yer alan panel regresyon sonuçlarına bakıldığında bağımsız değişkenlerin bağımlı değişkeni etkileme gücü yaklaşık olarak \%25'tir. Modelde yer alan enflasyon ve işsizlik değişkenlerine ait katsayılar ile model sabitine ait katsayının \%95 güven düzeyinde istatistiksel olarak anlamlı olduğu tespit edilmiştir. Değişkenlerin katsayılarına göre, enflasyon oranında meydana gelen 1 birimlik artış gelir dağılımı eşitsizliğini yaklaşık \%0.19 artırmaktadır. İşsizlik oranında meydana gelen 1 birimlik artış ise, gelir dağılımı eşitsizliğini yaklaşık \%0,71 arttırmaktadır. Enflasyon ve işsizlik oranlarının gelir dağılımı eşitsizliği üzerindeki etkisinin artırıcı yönde olması 
literatürdeki beklentilere uymakta ve literatür ile desteklenmektedir. Ayrıca modelde büyüme oranları modele dahil edilerek etkisi gözlemlenmiş ancak yapılan analizlerde ilgili verilerin katsayıları istatistiki olarak anlamsız çıktığı için nihai modelde yer verilmemiştir. Analiz sonucunda enflasyon oranında yaşanan artışların az da olsa gelir dağılımı adaleti üzerinde bozucu bir etki yaratığı gözlemlenmiştir. Model genelinde elde edilen sonuçlar, literatür ile uyumludur. Yani enflasyon oranlarındaki artışın gelir dağılımı adaletini doğrudan bozmaktan ziyade, enflasyon artışlarının sonuçlarının gelir dağılımı adaletini olumsuz etkilediği sonucuna varılmıştır. Model genelinde literatür ile uyumlu sonuçlara ulaşılmışıtır.

\section{Sonuç}

$\mathrm{Bu}$ çalışmada, 2002-2016 yılları arasında enflasyon hedeflemesi stratejisini uygulayan 8 gelişmiş ve 8 gelişmekte olan toplamda 16 ülke için, gerçekleşen enflasyon oranı ve gelir dağılımı arasındaki ilişki sabi etkiler panel veri analizi kullanılarak incelenmiş̧tir. Aynı zamanda, modelin bir bütün olarak yorumlanabilmesi için büyüme ve işsizlik oranları da modele dahil edilmiştir. Fiyat istikrarını sağlamaya yönelik uygulanan enflasyon hedeflemesi stratejisi, seçilmiş ülkelerde enflasyonun kontrol altına alınması bakımından olumlu sonuçlar ortaya koymuştur. Ülke ekonomilerinde iktisadi büyüme veya düşük enflasyonun gelir dağılımını pozitif yönde etkilerken, uzun dönemde Gini katsayısında iyileşme olmaması birçok çalışmaya konu olmuştur.

Çalışma genelinde enflasyonun gelir dağılımı üzerindeki etkisi ortaya konmaya çalışılmışıtır. Sonuç olarak enflasyonun gelir dağılımı üzerinde olumsuz bir etkiye sahip olduğu sonucuna ulaşılmışırı. Bir toplumda elde edilen çıktının adil dağılımı için, ülke ekonomilerinde bir taraftan ekonomik büyüme yaşanırken, diğer taraftan enflasyon ve işsizlik oranlarının da düşmesi gerekmektedir. Ancak sadece ekonomik göstergelerdeki iyileşmeler bir toplumun refah düzeyinde iyileşme kaydedilebilmesi için yeterli değildir. Gelir dağılımında eşitliğin sağlanabilmesi için, büyüme, enflasyon ve işsizlik gibi ekonomik göstergelerin yanında soysal, siyasal ve kültürel gibi birçok alanda ilerlemenin kaydedilmesi gerekmektedir. Ekonomik büyüme ile birlikte kazanılan ivme, enflasyon ve işsizlik oranları üzerinde olumlu etki yapmıyorsa, gelir dağılımı eşitsizliğinde artış kaçınılmazdır. Gelir dağılımı adaletsizliği, elde edinilen gelirin yoksuldan zengine doğru bir aktarım içinde olduğunun bir göstergesidir aslında. Bu nedenle gelir dağılımı adaleti için sadece bu değişkenler üzerinden politikalar yürütmek için yeterli olmayacaktır. Gelir dağılımı ekonomik olduğu kadar sosyal ve siyasi politikalar sonucunda oluşan bir sorundur. Bu yüzdendir ki gelir dağılımında eşitliğin kısmen de olsa sağlanabilmesi için özelde Türkiye ekonomisinde çok önemli yapısal düzenlemeler yapılması gerekmektedir.

Analiz sonuçları ile birlikte enflasyon ve gelir dağılımı arasındaki ilişki bakımından genel bir değerlendirme yapılacak olursa; uzun süreli yüksek enflasyonla mücadele, ülke ekonomilerine birçok yönden zarar vermektedir. Bir ülkenin kalkınmasında sadece makroekonomik göstergeler değil, aynı zamanda sosyal göstergeler de önem taşımaktadır. Fiyat istikrarı ve büyüme, ekonomik ve sosyal göstergelerin iyileşmesinde yeterli değildir. Bir ekonomide fiyat istikrarı sağlanarak elde edilen Gayri Safi Milli Hasıla ne kadar önemliyse, toplam çıktının toplum bireyleri arasında nasıl bölüşüldüğü 
Enflasyon Hedeflemesi Stratejisi Uygulayan Ülkelerde Gerçekleșen Enflasyon Oranı ve Gelir Dağılımı Arasındaki İlișki: Panel Veri Analizi

de bir o kadar önemlidir. Güçlü bir ekonomi için makroekonomik göstergeleri bir bütün olarak değerlendirmekte fayda vardır. Çünkü toplumsal refah artırılamadığı sürece ekonomik olarak büyüme tek başına anlamsız kalacaktır.

\section{Kaynaklar}

Akyazı, H. ve Ekinci, A. (2008). Enflasyon Hedeflemesi Rejiminin Performansı: Gelişmekte Olan Ülkeler ve Türkiye Karşılaştırması. Marmara Üniversitesi I.I.B.F. Dergisi, 2 (24), 21-37.

Akyazı, H. ve Ekinci, A. (2008). Enflasyon Hedeflemesi Rejiminin Performansı: Gelişmekte Olan Ülkeler ve Türkiye Karşılaştırması. Đ.Đ.B.F. Dergisi, XXIV, 1.

Alparslan, M. ve Erdönmez, P. (2000)."Enflasyon Hedeflemesi", Bankacılar Dergisi, Say1 35

Branco W. ve J. Williams, (1988), "Economic Development and Income Distribution: A Cross-National Analysis", American Journal of Economic and Sociology, Vol.47, No.3.

Bulir, A., (2001) Income inequality: does inflation matter?, IMF Staff Papers, 48 (2001) (1).

Güder,F. ve Kurt, S. (2018), "Makro ekonomik değişkenlerin gelir adaletsizliği üzerine etkileri: BRIC-T ülkeleri için panel veri analizi”, International Journal of Social Sciences and Education Research Online, http://dergipark.gov.tr/ijsser Volume: 4(3), 2018

Gülmez, A. ve Altıntaş, N. (2015)," Türkiye'de ticari açıklık ve enflasyonun gelir dağılımına etkisi: ekonometrik bir analiz" Kafkas Üniversitesi İktisadi ve İdari Bilimler Fakültesi KAÜ IIIBF Dergisi, Cilt 6, Sayı 9, 2015 ISSN: 1309 - 4289

İzgi, B., B., ve Alyu, E.(2018). Yoksulluk ve Gelir Dağılımı Eşitsizliği: OECD ve AB Ülkeleri Panel Veri Analizi, Gaziantep University Journal of Social Sciences, 17 (3), 9887-996.

Narin, M. ve Kutluay, D. (2013), "Değişen küresel ekonomik düzen: BRIC, 3G ve N-11 ülkeleri”, Dosya Dergisi, Ankara Sanayi Odası Yayını, ss.30-50.

Öztürk, S. (2009). Enflasyon Hedeflemesi Yaklaşımı: Gelişmiş ve Gelişmekte olan Ülkelerin Karşılaştırmalı Analizi. Celal Bayar Üniversitesi İ.I.B.F. Yönetim ve Ekonomi Dergisi, 16 (1), 192-205.

Panizza, U. "Income Inequality and Economic Growth: Evidence from America Data", Journal of Economic Growth, Vol.7.

Persson T. ve G. Tabellini, (1994), "Is Inequality Harmful for Growth", The American Economic Review, Vol.84, No.3.

Saraç, T.B., (2009), "Enflasyon ve Ekonomik Büyüme İlişkisi: Türkiye Ekonomisi Üzerine Ekonometrik Bir Uygllama (1988-2007)", Selçuk Üniversitesi Sosyal Bilimler Enstitüsü İktisat Anabilim Dalı, Doktora Tezi.

Şentürk,M. ve Akbaş, Y.E.(2014), “ İşsizlik-enflasyon ve ekonomik büyüme arasındaki karşılıklı ilişkinin değerlendirilmesi: Türkiye örneği”, Journal of Yasar University, 2014 9(34) 5820-5832. 
Yeldan, E. (2000), "The Impact of Financial Liberalization and the Rise of Financial Rent on Income Inequality the Case of Turkey", WIDER Working Paper Series, WP No. 206.

Yılmaz, G.Ö., (2005), "Türkiye Ekonomisinde Büyüme ile İşsizlik Oranları Arasındaki Nedensellik İlişkisi” İstanbul Üniversitesi İktisat Fakültesi Ekonometri ve Istatistik Dergisi, Say1: 2, ss. 63-76.

Yılmaz, Ö. ve Kaya, V., (2007), "Bölgesel Enflasyon Bölgesel Büyüme İlişkisi: Türkiye İçin Zaman Serisi ve Panel Veri Analizleri", Íktisat İşletme ve Finans, Sayı: 247, ss. $62-78$

Yumuşak, İ.G. ve M. Bilen (2000), 'Gelir Dağılımı - Beşeri Sermaye İlişkisi ve Türkiye Üzerine Bir Değerlendirme' Kocaeli Üniversitesi, Sosyal Bilimler Dergisi, Y11:2000, Say1: 1, s.77-96.

Yüceol, H. M., (2006), "Türkiye Ekonomisinde Büyüme ve İşsizlik İlişkisinin Dinamikleri", İktisat, İsletme ve Finans Dergisi, Y11: 21, Say1: 243, Haziran, ss. 81-95.

Eroğlu, N., Altaş, D., Ün, T. ve Ulu, M. İ. (2017). OECD Ülkelerinde Sosyal Yardım Harcamalarının Gelir Dağılımına Etkisi: Panel Veri Analizi. Uluslararası Ekonomik Araştırmalar Dergisi, 3 (3), 335-354. 